\title{
Dewey on Organisation
}

\section{Stephen Pratten}

\section{(2) OpenEdition}

\section{Journals}

Electronic version

URL: http://journals.openedition.org/ejpap/1671

DOI: 10.4000/ejpap.1671

ISSN: 2036-4091

\section{Publisher}

Associazione Pragma

Electronic reference

Stephen Pratten, «Dewey on Organisation », European Journal of Pragmatism and American Philosophy [Online], XI-2 | 2019, Online since 24 December 2019, connection on 16 June 2020. URL : http:// journals.openedition.org/ejpap/1671 ; DOI : https://doi.org/10.4000/ejpap.1671

This text was automatically generated on 16 June 2020.

\section{(c) (†) $\odot$

Author retains copyright and grants the European Journal of Pragmatism and American Philosophy right of first publication with the work simultaneously licensed under a Creative Commons AttributionNonCommercial-NoDerivatives 4.0 International License. 


\title{
Dewey on Organisation
}

\author{
Stephen Pratten
}

\section{AUTHOR'S NOTE}

For helpful comments on an earlier version of this paper I am grateful to two anonymous referees of the Journal and to the editors of this special issue.

\section{Introduction}

Certain contributors to contemporary debates about emergence emphasise the importance of the category of organisation. More specifically, some who defend a form of ontological emergence, including Tony Lawson as part of his distinctive perspective in social ontology and Bickhard and Campbell in the interactionist framework they forward, set out a particular conception of organisation. ${ }^{1}$ They argue that as long as ambiguities associated with the term are avoided then the category of organisation underpins a coherent account of emergent phenomena. Once organisation is given sufficient prominence and a particular meaning then it is shown by these authors that a compelling account of causal and ontological irreducibility follows, and confusions associated with the notion of downward causation resolved. Both these projects also see the mode of organisation characteristic of phenomena at different levels as grounding the possibility of the development of relatively autonomous sciences.

Dewey, especially in some of his later contributions, places considerable emphasis on the category of organisation. He makes reference to organisation in numerous contexts. For example, organisation is a central theme in Experience and Nature and a particular preoccupation in Chapter VII where he develops an emergent theory of mind. In that chapter he warns of the dangers associated with paying insufficient attention to organisation, suggesting that: "Organization is so characteristic of the nature of some events in their sequential linkages that no theory about it can be as speculative or absurd as those which ignore or deny its genuine existence." (Dewey 1925: 255). Earlier in the book he had linked the inadequacies of nominalism to its 
failure to sufficiently recognise organisation: "Nominalism ignores organization and thus makes nonsense of meanings." (Ibid.: 185). He is also concerned in the book to explore how life and mentality can be understood as reflecting different conditions of organisation. The category of organisation features prominently elsewhere in his later writings, in The Public and its Problems it is central to his understanding of the community. He writes: "a community as a whole involves not merely a variety of associative ties which hold persons together in diverse ways, but an organization of all elements by an integrated principle." (Dewey 1927: 38; italics in original). Given the emphasis that Dewey places on the category of organisation in his later writings it is worthwhile considering both what he means by the term and why he sees paying it sufficient attention as necessary if certain common errors in philosophy and social theory are to be avoided.

2 In order to explore the meaning and significance that Dewey attaches to the category of organisation I draw a comparison between Dewey's treatment of organisation (and related categories such as structure and association) in some of his later writings and the use of the term in strands of the contemporary debates on emergence. Initially I argue that a common understanding of organisation and its importance can be discerned in both Tony Lawson's work on social ontology and in the interactivist perspective developed by Bickhard and his colleagues. Even though in essence the conception of organisation is the same in these two contemporary projects it is useful to consider both of these lines of recent research since the clarifications offered and illustrations deployed are rather different. By reviewing the relevant aspects of both these projects a fuller appreciation of their shared account of organisation is facilitated. I then show how this conception of organisation provides a useful basis from which to interrogate Dewey's earlier emphasis on organisation. The meaning and significance attached to the category of organisation in these contemporary projects provides a fresh perspective from which to consider Dewey's own concern with organisation and related terms. It is shown that in some of his later contributions Dewey anticipates important aspects of this more recent treatment of organisation.

\section{Organisation, Reductionism and Downward Causation}

3 The category of relational organisation is central to the ontological framework that Tony Lawson has recently developed and his view of how to account for emergent phenomena. As Lawson notes: "the components of emergent entities (unlike members of aggregate collections) do what they do qua components only because of the manner in which they are organised (arranged, structured or related) as parts of the whole." (Lawson 2012: 351). Significantly Lawson emphasises that if we retain the customary terminology used in discussions of emergence of higher and lower levels then relational organisation needs to be both distinguished from the higher level emergent totality, whole or system and recognised as itself being a higher rather than lower level feature if emergence (understood as the appearance of novelty) ${ }^{2}$ is to be adequately accounted for.

4 The totality is that which is organised, it is a concrete entity that has the relational organisation and this organisation may be shared with other such entities. New totalities are constituted by the new higher level relational organisation that constrain 
the degree of freedom of their lower level components. Lawson argues that as the totality emerges so too does the relational organisation, without the latter there is no emergent totality merely a disorganised heap. He writes: "My contention is simply that the organisation of the lower level phenomena is itself always a novel phenomena, emerging along with any higher level totality. In other words the relationalorganisation itself must be regarded as a higher (not lower) level feature, and indeed a causal property of the emergent totality or entity." (Lawson 2012: 351-2).

Where discussions of emergence often go wrong, Lawson argues, is precisely in failing to pay enough attention to the category of relational organisation or in understanding it in only highly partial lower level terms. He notes: "relational-organisation, which entails an arrangement of lower level elements, is very often left largely under elaborated or little discussed, and treated implicitly as part of the lower level and mostly as a given." (Ibid.: 351). Relational organisation rather than being understood as a constitutive constraint is too often, he suggests, treated as trivial non-constitutive properties of some set of more basic ultimately unorganised lower level components.

6 The interactivist framework developed by Bickhard and his associates is another ambitious ontological perspective where the category of organisation is understood as being central and indispensable if issues related to emergence are to be clarified adequately. For interactivists constituting organisation is seen as a locus of causal power and more than simply the stage setting for more basic causal actors: "Emergence is supposed to occur with new patterns of organisation. Clearly something new comes into existence: the pattern itself. But in order for emergence to have any metaphysical significance, something new that has its own causal efficacy some manner in which that which is new has consequences for the future of the world must come into existence." (Bickhard 2010: 210). Just as Lawson makes a clear distinction between totalities and the relational organisation which give the former their distinctive properties and argues that both are higher level features, interactivists also insist that complex systems and the constituting organisations in virtue of which the former have their typical characteristics and modes of operation must be distinguished from one another and each acknowledged as higher level phenomena. Thus Richard Campbell suggests that the constituting organisation of a complex system captures "the way its constituent processes are constrained and regulated over time such that the integrity of the total system remains relatively stable and in virtue of which it has its typical characteristics and typically operates" (Campbell 2011: 65).

7 Interactivists argue the structural relations which configure constituents into a stable object belong to the whole object and they highlight that such configurations are macro-properties and not on the same level as the subsystems thus configured and therefore upper level features every bit as much as the complex total system. Campbell writes "The organization of any complex system is a macro-property of that system, constituted by the relations which configure its subsystems into specific dynamic patterns" (Campbell 2015: 261). Interactivists argue that it is a mistake to interpret organisation as a lower level property: "Since the structural relations which configure lower-level entities and activities into a whole system belong to the system as a whole, they are not on the same level as the properties of what is thus configured." (Ibid.: 220). For interactivists an adequate account of emergent phenomena can only be developed once organisation is recognised as a higher level feature "it is how [...] constituents are organized which generates the novel, higher level properties - and that organization is 
a holistic, macro level feature, not a property of its constituents. And the properties it generates are indeed emergent." (Ibid).

8 For Lawson and the interactivists a certain form of causal pluralism accompanies their emphasis on distinguishing the relational (or constituting) organisation from the structured totality and acknowledgment of their simultaneous emergence. There are entities at both the higher and lower levels and these entities possess distinct sets of efficient causal powers but as the entity at the higher level emerges so too does its relational organisation and this is also causal but in a different way. Lawson illustrates using the example of a house under construction:

The components include bricks, mortar, wood, panes of glass, cement, etc. Of course there will be a context, a plot of land, and this will be prepared so that the various components can relate to it in an appropriate manner. At any stage in the process of construction an observer will find not only the part of the building constructed so far, formed out of various components, but also the relational organisation of the latter components (to each other, and to elements in their environment). And this organisation will be essential to the house's construction and properties. As the house is completed, so is the relational organisation of the house's components; the two - the totality and the organisational structure - emerge simultaneously. Each are causal, but in different ways. The house has the power to provide safety and shelter, to facilitate family or other indoor activities, to be bought and sold and so on. The arrangement of the parts makes the house feasible. The latter is a form of formal causation. (Lawson 2013: 64)

In similar fashion interactivists emphasise the need to avoid the error of collapsing all forms of causality onto efficient causality. Constitutive organisation is specifically associated with a version of formal causality. Richard Campbell notes that "those properties which are dependent upon the mode of organization of a system's constituent parts are not the same as the properties of those parts. Different sets of similar constituents can manifest over time the same dynamic constituting organization in this sense, and generate the same kinds of properties and powers. If we think of the difference between kinds of entities as arising from their having relatively stable, cohesive but different forms of organisation, constituting organization proves to be the contemporary and temporalized analogue of an Aristotelian form." (Campbell 2011: 66).

Lawson and the interactivists recognise that proponents of ontological and causal reductionism often seek to ground their position by identifying some ultimate or basic entities that themselves are viewed as lacking organising structure. Once such a foundational level is posited then all higher level entities can be seen as being composed from these basic building blocks and then often only causation at this level of elementary and simple entities is seen as being of real or proper scientific concern. Both Lawson and the interactivists argue that once organisation is sufficiently recognised then these forms of reductionism can be easily resisted. Lawson notes that even were it possible to identify any such unstructured, basic entities this would not yet shore up claims of ontological and causal reducibility since the emergence of any higher-level causal properties would still depend upon how the lower level (fundamental) elements were organised, i.e., relational organisation would still be a formal causal factor. Thus, even with these assumptions any higher-level causation, being a real property of emergent forms of organisation, would like the relational structure from which it derives, be synchronically irreducible and so warranting of 
scientific investigation at its own level despite the supposedly fundamental nature of the elements so organised.

11 Lawson goes on to suggest that the best available interpretations of modern physics provide no support for the idea that there are any simple, unstructured, basic entities that might constitute some such foundational level. He writes: "according to quantum field theory, or at least its seemingly more explanatory powerful interpretations, if there is anything that underpins everything else it is quantum field processes and the phenomena that appear to be particles are the resulting effects of the quantisation of field excitatory activity. The particle-like elements are in fact said to be 'quanta of excitation or field quanta.' As such they are effectively emergent forms of organisation displaying particle like behaviour." (Lawson 2012: 356). For Lawson an implication of this kind of interpretation is that any reductionist style privileging of one particular level of organisation over all others is unjustified since "although there are, or can be, relations of dependency between organisations at different levels, there need be no ultimate or base level in quantum field theory, and so no reason for asserting that any one pattern or organisation of process is more fundamental, elementary, genuine, real or basic than any other; all remain of potential interest to science" (ibid.: 356).

Interactivists also emphasise that even where properties of the higher level system may be accounted for in aggregative terms organisation nonetheless remains fundamental. Campbell writes that where:

"cohesive systems" (i.e., entities) are formed, in many cases one can speak of their having components as their proper parts. Typically such entities manifest properties different from those of their parts. With respect to certain properties, this difference is merely one of quantity; the whole has at least some properties of the same kind as its proper parts. Such properties do result from an aggregation of the properties of their components [...] In such cases, the properties of the whole can be explained by an exhaustive and exclusive decomposition of the system into its proper parts. Nevertheless, it is important to note that, even in cases like this, more is involved in being a cohesive and causally effective aggregate than simply the arithmetical sum (that is, a bare conjunction) of its components. Those components have to stick together, somehow or other, in order to constitute a cohesive entity - and sticking together requires internal bonds between the components. (Campbell 2015: 204)

Interactivists also draw on interpretations of modern physics to suggest that ultimately it seems unlikely that there are any basic particulars which themselves lack organisation and form the fundamental constituents out of which everything in the world is composed. According to Campbell and Bickhard:

From the beginning of the twentieth century, physics has been dogged by a series of deep theoretical inconsistencies that are not yet fully resolved. But enough theoretical progress has been made for some conclusions of metaphysical significance to be drawn. What our best contemporary physics reveals is that there are no elementary particles, elemental events, or some such particulars; everything is composed of quantum fields of various scales and complexity. Quantum field theory shifts the basic ontology of the universe from micro-particles to quantum fields in process. What have seemed to be particles are now conceptualised as particle-like processes and interactions resulting from the quantization of field processes and interactions. (Campbell \& Bickhard 2011: 45)

14 From the kind of perspective developed by Bickhard et al, the world consists of organised fields of process all the way down and all the way up, there is no privileged base level. Campbell writes: 
The development of physics since the beginning of the twentieth century has provided explanations of how quantum fields are organized in various ways so as to yield the different kinds of elements ordered in the periodic table. And chemical theory has explained how those various atoms combine to produce even richer variety of kinds of molecule. It follows that the world is composed of organized fields in process - all the way down and all the way up. Everything there is has now to be understood as emerging from organizations of energy. (Campbell 2015: 70)

Discussions of emergence are often bound up with the notion of downward causation. Lawson is critical of how many of these discussions of downward causation are formulated viewing them as often being thoroughly confused (Lawson 2012: 352). He worries that the notion of downward causation often ends up encouraging the acceptance of a picture that disguises the importance of relational organisation by depicting two levels of entities moving as it were in parallel, with entities at the lower level causally acting upwards and wholes or totalities at the higher level also having efficient causal impacts on their parts. As noted above Lawson argues that it is important to carefully distinguish between any emergent system or totality and the organisational relational structure of the system's components. While these two - the totality and the relational organisation - emerge simultaneously they are not identical, they make a difference in distinct ways. He states that when adopting a diachronic (as opposed to a synchronic) criterion for distinguishing levels both the organising structure and the totality lie at the higher level. There are social systems or totalities with their own efficient causal powers. However, the organising relations also make a difference, they do so through a type of formal causation influencing how the components interact. The totality is then the sum of its constituent components and the organising relational structure and causally acts through rather than on its components. Lawson notes:

Wholes act through their parts acting and their parts are coordinated in their actions through the emergent irreducible relational structures that organise the lower level elements as (perhaps through modification) components of emergent wholes [...]. Thus, an army attacks through the actions of its soldiers (or guided weapons); a school educates through the interactions of its members; a football team scores through a player scoring. Parts of a whole though interact with, and relate directly to, not a whole but each other and the organising structure. (Lawson 2015: 6)

Lawson further illustrates by referring to the familiar example of a crowd. The crowd certainly emerges through individuals interacting in a context and this emergent totality has powers of efficient causality so, for example, traffic may be delayed as walking on the relevant roads takes precedence over driving. Crucially though, the individuals in their interactions draw not on the crowd behaviour as a totality but on the relational structure that organises individuals as components of the latter. So Lawson notes:

With any crowd a somewhat novel organising relational structure emerges (and is continually reproduced and/or transformed). Individuals are obliged to walk in a given direction, to seek to avoid colliding with others, and so move at an emergent speed. Also rights of interaction can emerge that, in different contexts, are not typically readily open to relative strangers [...] But always the organisational structure that emerges will be formed out of pre-existing context specific collective practices, including the rights and obligations they carry. (Lawson 2013: 71)

For Lawson if downward causation is used to express the idea that an entity or whole (synchronically) causally impacts upon its parts then the notion is simply untenable. A 
whole cannot act in this manner since the whole is composed out of the latter. Much of the discussion of downward causation is problematic, according to Lawson, because it fails to consistently draw the distinction between emergent totalities and the organising structures on which they depend, an error that he speculates is encouraged by the two distinct inflections associated with the term organisation: "In processes of emergence the lower level elements become organised as components of the emergent entity or whole, and so we can refer to the organisation of the components. But the category organisation is also regularly employed to refer to the totality including the lower level elements that have become (re)organised." (Lawson 2012: 352).

Interactivists express similar concerns about the relative neglect of organisation when they question the coherence of conventional talk of "emergent bases" within the literature on emergence. They highlight that it is far from clear that the notion of emergence base is coherent once organisation as a holistic relational feature is acknowledged. Campbell elaborates using the familiar example of water. He writes that in the case of water:

it seems simple to specify the base from which a molecule of water emerges: it is those atoms [of hydrogen and oxygen]. The implicit claim is that the proper parts of a molecule of water are two atoms of hydrogen and one atom of oxygen, and nothing else. But that is too simple; some force holds the atoms in a molecule together. A more sophisticated and informed version of this claim would acknowledge the forces within the molecule, but give them a particle interpretation. Thus, the proper parts of a molecule of water would be two atoms of hydrogen and one atom of oxygen, plus elementary particles whose exchanging holds the molecules together. This, however, is still inadequate. There is more to a molecule of water than two hydrogen atoms and one oxygen atom plus some elementary particles; there is the pattern of the relationship between them, and that patterning of the process, its organization, is what determines the emergent properties of water. (Campbell 2015: 198)

Interactivists have tended to persevere with the term downward causation but seem sensitive to the kinds of distinctions Lawson views as crucial if a coherent account of emergent phenomena is to be elaborated. For example, as noted earlier, interactivists interpret the kind of influence that constitutive organisation has as a type of formal causality. The higher level constitutive organisation is construed as constraining the efficient causal interactions between the system's components by selecting among a wide set of interactional possibilities (Bickhard \& Campbell 2003). Indeed downward causation seems to be a label used to refer to this formal influence of the constitutive organisation with respect to its parts.

For both Lawson and the interactivists organisation serves to ground the relative autonomy of the individual sciences. All forms of established science, according to Lawson, have objects of study that are effectively emergent forms of organisations and each science is especially concerned with the irreducible causal properties of the entities that populate their respective domains of study. So, for example, it is - he suggests - precisely because the social realm has a distinct mode of organisation that a relatively autonomous social science remains entirely feasible. From the interactivist group Campbell, deploying the language of levels, writes: "we should note that each level is defined by the kinds of entity ('object') with their distinctive modes of interaction, which exist on that level. The distinctive entities, properties, and interactions which define a level constitute the domain of a particular science. That is the categorical inferences licensed by an individual science imply an ontology of 
entities of a certain kind or kinds, possessing distinctive properties and distinctive modes of interaction." (Lawson 2015: 196). ${ }^{3}$

\section{Dewey on Organisation, Structure and Association}

21 There are striking correspondences between the characterisation of (and significance attached to) organisation in the contributions of Lawson and the interactivists and that found in certain of Dewey's later contributions. Dewey too highlights the need to pay close attention to the category of organisation if prominent types of error in philosophy as well as social theory are to be avoided. The commonalities are especially pronounced where Dewey (writing with Sidney Hook and Ernest Nagel) responds to criticisms concerning the form of naturalism and materialism they are taken to advocate. In clarifying their shared position they address issues that would now be linked to debates about reductionism and downward causation.

Dewey and his associates argue that it is a significant mistake to regard some structured unity and its properties as in any sense being separated off from its parts and their organisation and capable of directly controlling its constituents in some external, unmediated fashion. In elaborating upon this theme, they emphasise the need to recognise the significance of organisation. In order to illustrate the relevant issues they consider the example of water molecules:

For suppose a chemist were asked whether he believed that the properties of water are at "the beck and call" of hydrogen and oxygen atoms, or whether he thought that water "controlled" the behaviours and properties of its constituents. Would he not reply that the questions are meaningful only on the assumption that the properties of water are not only distinguishable from those of its constituents taken singly or in isolation from each other, but are also substantially distinct from the properties of hydrogen and oxygen atoms when these are related in the way in which water molecules are organized? On the other hand, the chemist would certainly maintain that the existence of water and its properties is contingent upon the combined presence of certain elements interrelated in definite ways. But he would call attention to the fact that when these elements are so related, a distinctive mode of behaviour is exhibited by the structured unity into which they enter. Nevertheless, this structured object is not an additional thing which, in manifesting its properties, controls from some external vantage point the behaviour of its organized parts. The structured object in behaving the way it does behave under given circumstances is simply manifesting the behaviour of its constituents as related in that structure under those circumstances. (Dewey, Hook \& Nagel 1945: 520-1; italics in original)

In a manner that anticipates the concerns Lawson raises against some contemporary accounts of downward causation, Dewey and his colleagues see any reification of structured unities and the attribution to them of the power to interact downwardly upon their own parts as highly problematic reflecting insufficient attention being paid to the relevant forms of relatedness through which the parts are organised. The existence of water depends on both individual components and organising relations. The structured unity cannot directly act on its parts since it is composed out of (and only acts through) the later. However, at any point in time the organising relations of the structured unity can and do make a difference to how the components interact. For Dewey and his collaborators the constituents of a sample of water do what they do as constituents of that structured unity only because of the manner in which they are organised (related or arranged). It is precisely when, and due to the manner in which 
the (pre-structured) constituents are so organised or related that the distinctive properties associated with water become feasible. It is only then that the organised component parts make the contribution they do to the structured object. The emergence of the structured unity and the organising structure is taken to be part of one and the same development. ${ }^{4}$

In parallel fashion Dewey, Hook and Nagel regard mentality as a quality emergent from a special organisation of physical processes, it is only the organised system of the living body as a whole that gives rise to the sensations experienced when certain brain states are activated. The emphasis is upon the need to distinguish between the organised whole and relational organisation and on seeing the two as arising together:

The naturalist proceeds in an essentially no different manner in giving his account of the status of minds. Like the chemist in reference to the properties of water, he maintains that the states and events called mental exist only when certain organizations of physical things also occur. And also like the chemist, he holds that the qualities and behaviours displayed by physical things when they are properly organized - the qualities and behaviours called mental or spiritual - are not exhibited by those things unless they are so organized. But these qualities and behaviours of organised wholes are not additional things which are substantially distinct from the properties and behaviours of spatio-temporal objects in their organized unity. Accordingly, naturalists most emphatically acknowledge that men are capable of thought, feeling, and emotion, and that in consequence of these powers (whose existence is contingent upon the organization of human bodies) men can engage in actions that bodies not so organized are unable to perform. In particular, human beings are capable of rational inquiry, and in the light of their findings they are able to "redistribute" spatio-temporal things so as to ensure the arrival and departure of many events both physical and mental. They achieve these things, however, not as disembodied minds, but as distinctively organized bodies. (Dewey, Hook \& Nagel 1945: 521-2; italics in original)

Dewey, Hook and Nagel conclude the relevant section by highlighting that organisation or arrangement is always central to the constitution of structured wholes and in accounting for their distinctive properties regardless of whether the focus is on water, minds or artefacts - such as clocks:

To the naturalist, at any rate, there is no more mystery in the fact that certain kinds of bodies are able to think and act rationally than in the fact that cogs and springs arranged in definite ways can record the passage of time or that hydrogen and oxygen atoms ordered in other ways display the properties of water. "Things are what they are, and their consequences will be what they will be; why then should we desire to be deceived?" (Ibid.: 522)

In this response the terms organisation, arrangement, order and relation seem to be used almost interchangeably. In Experience and Nature Dewey, at times, deploys the further term structure when considering the kind of organising relations characteristic of artefacts and uses the example of a house to illustrate. Just as with regard the category of organisation in the joint response to the critic considered above, Dewey when elaborating on this example insists that structure is a property of the totality the realised construction. The totality and the organising structure emerge for Dewey simultaneously, they are not identical and neither should be neglected. On Dewey's account it is the organising structure that makes the house feasible - it serves as a condition of its possibility. He argues that in recognising structure and its role it is necessary to avoid isolating it from the totality since to do so would be to encourage a 
confused understanding whereby organising structure is taken as somehow mysteriously existing without anything actually being organised. He writes:

A house has a structure; in comparison with the disintegration and collapse that would occur without its presence, this structure is fixed. Yet it is not something external to which the changes involved in building and using the house have to submit. It is rather an arrangement of changing events such that properties which change slowly, limit and direct a series of quick changes and give them an order they do not otherwise possess. Structure is constancy of means, of things used for consequences, not of things taken by themselves or absolutely. Structure is what makes construction possible and cannot be discovered or defined except in some realised construction, construction being, of course, an evident order of changes. The isolation of structure from the changes whose stable ordering it is, renders it mysterious - something that is metaphysical in the popular sense of the word, a kind of ghostly queerness. (Dewey 1925: 72)

For Lawson and the interactionists the focus on organisation grounds their rejection of causal and ontological reductionism. That is, they agree that an adequate recognition of organisation serves to counter any notion that emergent properties, including causal powers of emergent totalities, depend solely on and are entirely predictable from a knowledge of the properties of the various elements that are eventually organised as components. Dewey too is anxious to resist such forms of reductionism. At times this is expressed in general terms, for example, in Logic: A Theory of Inquiry he writes:

The primary postulate of a naturalistic theory of logic is continuity of the lower (less complex) and the higher (more complex) activities and forms. The idea of continuity is not self-explanatory. But its meaning excludes complete rupture on the one side and mere repetition of identities on the other; it precludes reduction of the "higher" to the "lower" just as it precludes complete breaks and gaps. The growth and development of any living organism from seed to maturity illustrates the meaning of continuity. (Dewey 1938: 23)

This kind of anti-reductionist stance encourages Dewey to take up the more concrete challenge of advancing powerful accounts of phenomena or systems that exist at various levels. In doing so, organisation is central to the discussion. His accounts of both life and mind in Experience and Nature are explicitly framed in terms of organisation. The category of organisation is important for Dewey's attempt to account for how such phenomena, while being fully integrated with the rest of the natural world, can still be meaningfully distinguished. It is in terms of their respective conditions of organisation and corresponding modes of interaction that he seeks to differentiate them from other types of phenomena and from one another. For Dewey "while there is no isolated occurrence in nature, yet interaction and connection are not wholesale and homogenous" (1925: 271). He writes:

As life is a character of events in a peculiar condition of organization, and feeling is a quality of life-forms marked by complexly mobile and discriminating responses, so "mind" is an added property assumed by a feeling creature, when it reaches that organized interaction with other living creatures which is language communication. (Ibid.: 258)

Fundamental to understanding the characteristic features of a domain is consideration of the relevant conditions of organisation. Life is understood by Dewey as being constituted by a complex organisation of natural sub processes (or events) and mind by an organisation of physiological processes:

Unless vital organizations were organizations of antecedent natural events, the living creature would have no natural connections; it would not be pertinent to its 
environment nor its environment relevant to it; the latter would not be usable, material of nutrition and defence. In similar fashion, unless "mind" was, in its existential occurrence, an organization of physiological or vital affairs and unless its functions developed out of patterns of organic behaviour, it would have no pertinency to nature, and nature would not be the appropriate scene of its inventions and plans, nor the subject matter of its knowledge. (Ibid.: 286) observation that: "Personality, selfhood, subjectivity are eventful functions that emerge with complexly organized interactions, organic and social." (Ibid.: 208).

In Experience and Nature Dewey is not satisfied with simply noting how organisation is central to differentiating types of phenomena but also explores, in an empirically informed manner, the conditions of organisation and modes of interaction distinctive of living organisms. In considering what distinguishes the living body from the inanimate he focuses in on that specific form of organisation in which the interactions are regulated in such a way as to maintain the system in being as an integral whole despite variations in external conditions:

The interactions of the various constituent parts of a plant take place in such ways as to tend to continue a characteristically organized activity; they tend to utilize conserved consequences of past activities so as to adapt subsequent changes to the needs of the integral system to which they belong. Organization is a fact, though it is not an original organizing force. Iron as such exhibits characteristics of bias and selective reactions, but it shows no bias in favour of remaining simple iron; it had just as soon, so to speak, become iron-oxide. It shows no tendency in its interaction with water to modify the interaction so that consequences will perpetuate the characteristics of pure iron. If it did it would have the marks of a living body, and would be called an organism. (Ibid.: 254)

Both with regard the mind and the distinctively social Dewey is similarly concerned to give further content to the specific condition of organisation he sees as distinguishing these phenomena. For Dewey it is important to recognise that we are both embodied and yet emergent always in essential interaction with our environments and cultures. He writes:

"body-mind" simply designates what actually takes place when a living body is implicated in situations of discourse, communication and participation. In the hyphenated phrase body-mind, body designates the continued and conserved, the registered and cumulative operation of factors continuous with the rest of nature, inanimate as well as animate; while "mind" designates the characters and consequences which are differential, indicative of gestures which emerge when " body" is engaged in wider more complex and interdependent situation. (Ibid.: 285)

The properties of mind on Dewey's account are grounded in, emergent from but irreducible to the living body.

When focussing in on the specifically human realm and how to distinguish it Dewey sometimes deploys the term association rather than organisation but it seems to serve a similar function. He writes:

Everything that exists in as far as it is known and knowable is in interaction with other things. It is associated, as well as solitary, single. The catching up of human individuals into association is thus no new and unprecedented fact; it is a manifestation of a commonplace of existence. Significance resides not in the bare fact of association, therefore, but in the consequences that flow from the distinctive patterns of human association. There is again nothing new or unprecedented in the fact that assemblage of things confers upon the assembly and its constituents, new properties by means of unlocking energies hitherto pent in. The significant

European Journal of Pragmatism and American Philosophy, XI-2 | 2019 
consideration is that assemblage of organic human beings transforms sequence and coexistence into participation. (Ibid.: 175)

\section{"Social as a}

If reference to association is to be anything more than a ceremonial and barren act of deference, if it is to be used in any enterprise of philosophic description and understanding, it indicates the necessity of study and analysis of the different modes of association that present themselves in experience. And the implication of our argument is that in such a comparison of definite types of association the social, in its human sense, is the richest, fullest and most delicately subtle of any mode actually experienced [...]. Association in general is but a matrix; its filling are the facts of association actually displayed in nature. Indeed, the category of association is but a highly abstract notion of what is formally common to the special modes. (Dewey 1928: 165)

According to Dewey social groups, such as the family, manifest properties and powers which are novel and distinctive:

[I]n the social the physical is taken up into a wider and more complex and delicate system of interactions so they take on new properties by release of potentialities previously confined because of absence of full interaction. The same consideration applies to the inclusion within the social of the vital or organic. The members of society are living beings with the characteristics of living creatures; but as these enter into distinctly human associations their strictly organic properties are modified and even transformed. Certain physiological factors of sex, of procreation, immaturity and need of care, are assuredly implicated in the functions expressed in family life. But however great the role of animal lust, there is something more in any family association than bare physiological factors. (Ibid.: 169-70)

For Dewey certain powers of coordinated interactions are available to individuals qua members of human communities that would not have emerged if human individuals were instead mere biological beings that just happened to be situated in close spacetime proximity. He insists that reductionist and supernatural interpretations of distinctively social phenomena can be avoided since given his general framework there is an obvious empirically compelling alternative understanding available:

The fact of transformation of the purely organic by inclusion within the scope of human association is so obvious - note the significant change of cries into speech that it has indeed led to belief in the intrusive intervention of unnatural and supernatural factors in order to account for the differences between the animal and the human. The disjunction between the assertion that the human is merely animal and the assertion that an extraneous force is obtruded is not however exhaustive. There remains an alternative which is most fully confirmed by empirical fact, namely that the difference is made when new potentialities are actualised, when the range of interactions that delimits the notion of the organic is taken into the wider and more subtly complex association which forms human society. (Ibid.: 170)

In elaborating upon his account of that form of association that is distinctively human Dewey in The Public and its Problems places particular emphasis upon the rights, duties and responsibilities that individuals acquire as they enter into different associations. His initial example is that of marriage. 
A single man when he is joined in marriage is different in that connection to what he was as single or to what he is in some other union, as a member, say, of a club. He has new powers and immunities, new responsibilities. He can be contrasted with himself as he behaves in other connections. He may be compared and contrasted with his wife in their distinctive roles within the union. But as a member of the union he cannot be treated as antithetical to the union in which he belongs. As a member of the union, his traits and acts are evidently those which he possesses in virtue of it, while those of the integrated association are what they are in virtue of his status in the union. The only reason we fail to see this, or are confused by the statement of it, is because we pass so easily from the man in one connection to the man in some other connection, to the man not as husband but as business man, scientific investigator, church member or citizen, in which connections his acts and their consequences are obviously different to those due to union in wedlock. (Dewey 1927: 189)

For Dewey individuals behave differently depending on the kind of integrated association they become enrolled into as in each case they will be faced with specific sets of rights and duties. He develops his theme by considering as a further illustration the modern corporation. The corporation is seen by Dewey as manifesting properties and powers which are novel and distinctive, not manifested by the singular human members who in part constitute it. Individuals within the corporation are given distinct statuses and the corporation itself is seen as acquiring certain rights. He writes:

A corporation as such is an integrated collective mode of action having powers, rights, duties and immunities different from those of its singular members in their other connections. Its different constituents have also diverse statuses - for example, the owners of stock from the officers and directors in certain matters. (Dewey 1927: 190 ; italics in original) common tendency, as he sees it, to reify structured unities now exploring how this manifests itself at the level of social ontology. Dewey is keen to emphasise that the corporation as an integrated association only acts through its components. The individuals who are parts of the corporation interact not with corporate behaviour as a totality but are faced with specific sets of rights and obligations and act on the basis of these and thereby contribute as an element in this specific form of integrated association:

Since the corporation can do things which its individual members, in their many relationships outside of their connections in the corporation, cannot do, the problem is raised as to the relation of the corporate collective union to that of individuals as such. It is forgotten that as members of the corporation the individuals themselves are different, have different characteristics, rights and duties, than they would possess if they were not its members and different from those which they possess in other forms of conjoint behaviour. But what the individuals may do legitimately as members of the corporation in their respective corporate roles, the corporation does and vice versa... An individual cannot be opposed to the association of which he is an integral part nor can the association be set against its integral members. (Ibid.: 188-9)

Dewey also draws on the corporation when seeking to illustrate the validity of and need for relatively autonomous social science research. Thus, in Experience and Nature corporations are understood as being entirely dependent on the interactions of human beings and yet an irreducible objective reality deserving scientific investigation every bit as much as electrons are. He writes: 
What is a Corporation, a Franchise? A corporation is neither a mental state nor a particular physical event in space and time. Yet it is an objective reality, not an ideal Realm of being. It is an objective reality which has multitudinous physical and mental consequence. It is something to be studied as we study electrons; it exhibits as does the latter unexpected properties, and when introduced into new situations behaves with new reactions. It is something which may be conducted, facilitated and obstructed, precisely as may be a river. Nevertheless, it would not exist nor have any meaning and potency apart from an interaction of human beings with one another, an interaction in which external things are implicated. (Dewey 1925: 197)

The implication here seems to be that the corporation is a system that has distinctive properties and is part of a social reality that has emerged (and continues to emerge) from non-social phenomena which constitutes a relatively distinct order requiring separate scientific study. ${ }^{6}$ Thus, like Lawson and the interactivists, Dewey maintains that at the level of the social there are real irreducible system features that constitute objects of knowledge and that will often only be understood through lengthy processes of scientific investigation.

\section{Concluding Remarks}

The category of organisation is central to the way that two contemporary projects account for emergent phenomena. Both Lawson's project in social ontology and the interactivist framework Bickhard and his collaborators develop highlight organisation as a fundamental category that once sufficiently elaborated serves to counter causal and ontological reductionism and resolve ambiguities associated with the notion of downward causation. Moreover, within these projects different modes of organisation ground the possibility of the development of relatively autonomous sciences.

Organisation, alongside related categories such as structure and association, feature prominently in certain of Dewey's later contributions. The emphasis on organisation in Dewey's later works anticipates the prominence the category receives in the two contemporary projects considered. In Experience and Nature and some other later works Dewey emphasises the need to recognise organisation so as to fend off reductionism and highlight the dangers of reifying structured unities and seeing them as capable of directly acting on their components/parts. Furthermore, Dewey defends the possibility of a scientific engagement with distinctively social phenomena. The pattern of association characterising social phenomena mean they are irreducible to lower level phenomena - he views corporations for example as being just as real as electrons and equally legitimate candidates for scientific investigation.

Insight regarding the significance Dewey attaches to organisation, and closely aligned categories such as structure and association, in some of his later contributions can be obtained by considering his relevant writings alongside the treatment of organisation found in modern projects that seek to systematically theorise organisation. The account of organisation and the importance attached to it in the two contemporary projects is anticipated to a significant extent by Dewey in some of his later writings. Despite the interesting correspondences and overlaps between the two contemporary projects considered and aspects of Dewey's later work there is no claim that these three projects are in any sense identical. While it can be shown that they share a broad emphasis on organisation and it serves a similar role in precluding ontological and causal reductionism, this does not mean that they characterise the modes of 
organisation operative at distinct levels in the same manner. Tracing out the similarities and differences in the characterisation of different modes or conditions of organisation would constitute a further project. ${ }^{7}$

\section{BIBLIOGRAPHY}

BICKHARD Mark H., (2009), “The Interactivist Model,” Synthese 166, 547-91.

BICKHARD Mark H., (2010), “Interactive Knowing: The Metaphysics of Intentionality," in R. Poli \& J. Seibt (eds), Theory and Applications of Ontology: Philosophical Perspectives, New York, Springer. BICKHARD Mark H., (2018), "Naturalism, Emergence, and Brute Facts," in E. Vintiadis \& C. Mekios (eds), Brute Facts, Oxford, Oxford University Press.

BICKHARD Mark H., \& Donald T. Campbell, (2003), "Variations in Variation and Selection: The Ubiquity of the Variation and Selective-Retention Ratchet in Rmergentist Organizational complexity," Foundations of Science 8, 215-82.

CAHOONE Lawrence, (2013), The Orders of Nature, New York, Suny Press.

CAMPBELL Richard J., (2011), The Concept of Truth, London, Palgrave Macmillan.

CAMPBELL Richard J., (2015), The Metaphysics of Emergence, London, Palgrave Macmillan.

CAMPBELl Richard J. \& Mark H. BICKHARD, (2011), "Physicalism, Emergence and Downward Causation," Axiomathes 21, 33-56.

DEWEY John, (1925), Experience and Nature, New York, Dover Publications.

DEWEY John, (1927), The Public and its Problems, Athens, Ohio University Press.

DEWEY John, (1928), "Social as a Category," The Monist, 38 (2), 161-77.

DEWEY John, (1938), Logic: The Theory of Inquiry, New York, Henry Hold and Company.

DEWEY John, НОок Sidney \& Ernest NAGEL, (1945), “Are Naturalists Materialists?,” The Journal of Philosophy, 42 (19), 515-30.

FAULKNER Phil, PRATTEN Stephen \& Jochen RUNDE, (2017), “Cambridge Social Ontology: Clarification, Development and Deployment," Cambridge Journal of Economics, 41 (5), 1265-77.

FREGA Roberto, (2019), Pragmatism and the World Wide View of Democracy, London, MacMillan Palgrave.

LAWSON Tony, (1997), Economics and Reality, London, Routledge.

LAWSON Tony, (2012), "Ontology and the Study of Social Reality: Emergence, Organisation, Community, Power, Social Relations, Corporations, Artefacts and Money," Cambridge Journal of Economics, 36 (2), 345-85.

LAWSON Tony, (2013), "Emergence and Morphogenesis: Causal Reduction and Downward Causation," in M. S. Archer (ed.), Social Morphogenesis, New York, Springer. 
LAWSON Tony, (2015), "The Nature of the Firm and the Peculiarities of the Corporation," Cambridge Journal of Economics, 39 (1), 1-32.

LAWson Tony, (2016a), “Comparing Conceptions of Social Ontology: Emergent Social Entities and / or Institutional Facts," Journal for the Theory of Social Behaviour, 46 (4), 359-99.

LAWson Tony, (2016b), “Some Critical Issues in Social Ontology: Reply to John Searle," Journal for the Theory of Social Behaviour, 46 (4), 426-37.

LAWson Tony, (2019), The Nature of Social Reality: Issues in Social Ontology, London, Routledge.

PRATTEN Stephen, (2013), “Critical Realism and the Process Account of Emergence," Journal for the Theory of Social Behaviour, 43 (3), 251-79.

PRATTEN Stephen, (2015), Social Ontology and Modern Economics, London, Routledge.

TESTA Italo, (2017), “Dewey's Social Ontology: A Pragmatist Alternative to Searle's Approach to Social Reality," International Journal of Philosophical Studies, 25 (1), 40-62.

\section{NOTES}

1. For discussion of key elements of the interactivist framework, a project initially located in the field of theoretical psychology, see Bickhard 2009, 2010 and 2018. Lawson 2019, Pratten 2015, and Faulkner, Pratten and Runde 2017 provide context regarding Lawson's contributions to social ontology. Lawson has long been located in the Economics Faculty at Cambridge University, his focus on social ontology was encouraged by a growing appreciation that the current disarray and explanatory failure of the economics discipline could only be accounted for by adopting an explicitly ontological orientation (see Lawson 1997). As he has elaborated his ontological project he has engaged with others promoting the study of social ontology - for a detailed comparison of Lawson's perspective with that advanced by John Searle, see Lawson $2016 \mathrm{a}$.

2. It is important to note that for Lawson emergence refers just to the appearance of novelty, it marks the spot where something new arises out of what already existed. Emergence is not itself seen by Lawson as doing any explanatory work. Thus, in an exchange with John Searle he writes: "I use the term emergence primarily to capture any processes whereby some pre-existing elements become organised into a totality or system, a system that is novel or unprecedented in relation to those elements and their context. In addition, I use the term emergent in reference to the totality itself, its causal properties, and the organisation of the elements. I do also express these developments by saying such novel features somehow emerge. However, the manner in which they do so is always a matter of investigation. None of the terms are interpreted as explanatory." (Lawson 2016b: 429).

3. For a broader comparison of Lawson's project in social ontology and the programme of research pursued by the interactivists, see Pratten 2013.

4. This example of water already appears in Dewey's The Public and its Problems where it serves the same purpose of highlighting the problem of treating the whole as an isolated entity capable of acting on its own parts. For Dewey it is important, whether considering social or natural systems, to recognise that the structured unity only ever acts through its parts as related or organised in a distinctive manner. He writes: "it is absurd to suppose that a society does away with the traits of its own constituents so that it can be set over against them. It can only be set over against the traits which they and their like present in some other combination. A molecule of oxygen in water may act in certain respects differently than it would in some other chemical union. But as a constituent of water it acts as water does as long as water is water. The only intelligible distinction which can be drawn is between the behaviours of oxygen in its different relations, 
and between those of water in its relations to various conditions, not between that of water and the oxygen which is conjoined with hydrogen in water." (Dewey 1927: 188-9).

5. The emphasis on the whole acting through its parts rather than directly upon its parts was already noted earlier in the same book: "Individual human beings may lose their identity in a mob or in a political convention or in a joint-stock corporation or at the polls. But this does not mean that some mysterious collective agency is making decisions, but that some few persons who know what they are about are taking advantage of massed force to conduct the mob their way, boss a political machine, and manage the affairs of corporate business. When the public or state is involved in making social arrangements like passing laws, enforcing a contract, conferring a franchise, it still acts through concrete persons." (Dewey 1927: 18).

6. The example of the corporation is indicative of Dewey's broader commitment that there are emergent structured unities that can become the focus for a series of relatively autonomous sciences. Dewey indicates this kind of view where he quotes Meyer with approval: "We recognise that throughout nature we have to face the general principle of unit-formation, and the fact that new units need not be a mere sum of the component parts, but can be an actually new entity not wholly predictable from component parts and known only through actual experience with the specific product." (Dewey 1925: 145). The recognition of the reality and causal relevance of a series hierarchically arranged complex systems and processes implies the existence of a number of orders of nature. For one contemporary attempt to distinguish between such emergent orders, which itself is informed by the work of Dewey and other pragmatists, see Cahoone 2013, where five orders of nature are examined - described as the physical, material, biological, mental and cultural.

7. A comparison of Lawson's account of the nature of social reality and Dewey's commitments at the level of social ontology would likely be especially valuable. Testa (2017) argues that Dewey's social ontology has certain strengths over that defended by John Searle. Lawson in a number of critical exchanges with Searle argues that the, ultimately, ideational social ontology that he takes Searle to be advancing fails to sufficiently recognise a practical dimension underpinning social interactions (see Lawson 2016a). An important theme to explore in any such comparison is whether, and in what sense, Dewey acknowledges such a practical dimension. The comparison could extend to an evaluation of how each project draws out the implications of their ontological positions for an understanding of social change, for Lawson's views on the possibilities for emancipatory social change see 2019, chapter 8 and for Dewey's interactionist social ontology of democracy, see Frega, 2019, chapter 4.

\section{ABSTRACTS}

In some of his later contributions Dewey places particular emphasis on the category of organisation. Organisation features prominently both in his later metaphysical writings and in some of his more substantively focussed contributions. Organisation is also a central category for two contemporary ontological projects, namely Tony Lawson's perspective on social ontology and the interactivist framework developed by Mark Bickhard and his collaborators. In these modern naturalist perspectives, the thorough theorisation of organisation is seen as crucial in accounting for emergent phenomena, resisting ontological and causal reductionism and resolving ambiguities associated with certain formulations of downward causality. This paper compares Dewey's remarks on organisation in his later writings with these contemporary 
treatments of organisation and argues that Dewey anticipates some of the insights that have been systematically set out in these modern programmes of research.

\section{AUTHOR}

\section{STEPHEN PRATTEN}

King's College London

stephen.pratten[at]kcl.ac.uk 